\title{
Experimental heat transfer analysis of Copper oxide nanofluids through
}

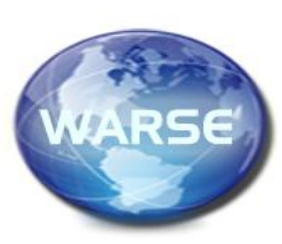
a straight tube

\author{
Parminder Singh ${ }^{1}$, Amandeep Singh Oberoi ${ }^{2}$, Parag Nijhawan ${ }^{3 *}$ \\ ${ }^{1,2,3}$ Thapar Institute of Engineering and Technology, Patiala, India \\ 1'parminder.singh@thapar.edu \\ 2 oberoi @thapar.edu \\ 3parag.nijhawan@rediffmail.com
}

\begin{abstract}
The presented research work focuses on forced convective heat transfer study carried out experimentally on metal oxide (copper oxide and magnesium oxide) based nanofluids under laminar flow regime inside a straight tube at constant wall temperature condition. Propylene glycol water mixture in 60:40 weight ratio is used as base fluid in which a measured quantity of $\mathrm{CuO} / \mathrm{PG}-\mathrm{W}$ ( 0.3 and $0.7 \mathrm{vol}$. $\%$ ) is added to get working nano fluid. It is found from the obtained results that heat transfer co-efficient of the prepared nano fluid is significantly higher than its base fluid. Maximum rise in Nusselt number is observed for highest volume concentration. The observed hike in both Nusselt number and heat transfer coefficient probably resulted from the combined effect of increased effective thermal conductivity of nano fluid, existence of Brownian motion, and random collision between the fluid particles and nanoparticles. From the observed data, empirical correlations are suggested for the prediction of Nusselt number for the above said nanofluids through straight tubes. Different statistical errors are also reported which account for $\pm 8 \%$. The presented experimental study and associated results would help to attain better understanding of the heat transfer behavior of copper oxide based nanofluids with numerous potential applications in the field of heat sinks and cooling of the electronic systems.
\end{abstract}

Key words: Copper Oxide Nanofluid; Propylene Glycol; Water; Straight Tube; Nusselt Number, laminar flow conditions.

\section{INTRODUCTION}

Commonly used fluids for convective heat transfer, like glycols, engine oil, water etc., have innately low thermal conductivity thus exhibits poor heat transfer performance. Hence, power savings and size reduction of the heat transfer systems motivate researchers to enhance the system performance and attain the required heat transfer. The thermal conductivity of heat transfer systems could be increased significantly with addition of certain metal or their oxide particles, properly dispersed in base fluids. Conductivity(thermal) of conventional base fluids, to a great extent, is dependent on size of solid particles that are mixed in it [1]. Besides high thermal conductivity, practical feasibility of these solid - liquid mixtures have experienced many problems such as homogenous solution stability, corrosion, high pressure drop and channel clogging.
Nanoparticles have numerous applications in the field of heat transfer viz. heat sinks, heat exchangers, radiators, automobile and electronic system cooling etc. and therefore, have attracted a large number of researchers to explore this area [2-8]. Nanofluids usually consist of engineered colloids of nanoparticles suspended in base-fluids with volume fraction of $0-5$ vol. $\%$; that offers resistance towards channel erosion, clogging and particle settling [9]. Various researchers have reportedly studied heat transfer and hydrodynamics of different nanofluids, for example,[10] carried out the thermal performance of $\mathrm{Al}_{2} \mathrm{O}_{3}$ and $\mathrm{TiO}_{2}$ nanoparticles in water base fluid under turbulent flow conditions. It was reportedly concluded that there was a significant increase in Nusselt number with increased volume concentration of nanofluids.[11-12] experimentally analyzed heat propagation through copper oxide-based nano fluid in a horizontal flat-tube heat exchanger working under laminar regime with boundary condition. Observed results showed the increased pressure drop due to the flat profile of tubes and heat transfer co-efficient due to the presence of nano fluid. [13] determined pressure drop and heat exchange characteristics of $\mathrm{Al}_{2} \mathrm{O}_{3}-\mathrm{Cu}$ /water-based hybrid nano fluid flowing in circular tubes under laminar flow conditions. For a Reynolds number of 1750, Nusselt number enhancement for nanofluids was $13.56 \%$ in comparison to the base fluid. The experimental data on the heat exchange and flow behaviors of propylene glycolbased nanofluids flowing in a straight tube is scarcely reported in literature. The present work thus, focuses on determination of thermal performance in terms of Nusselt number and of an aqueous propylene glycol-based copper nano fluid flowing in straight tubes at constant wall temperature. It is to be noted that all the reported experiments are conducted in a laminar flow regime. Based on the experimental findings generalized correlation is proposed for Nusselt number for different nanofluids.

\section{MATERIALS AND METHODS}

$\mathrm{CuO}$ nanoparticles used in experimental studies of (60:40, by wt.\%) aqueous propylene glycol solution was procured from US Research nano material laboratory. Figure 1 shows image of copper oxide $(\mathrm{CuO})$ nanoparticles suspended in base fluid taken by a scanning electron microscope. It is clear from the obtained image that $\mathrm{CuO}$ nanoparticles are spherical in shape with primary size of $38 \mathrm{~nm}$. 


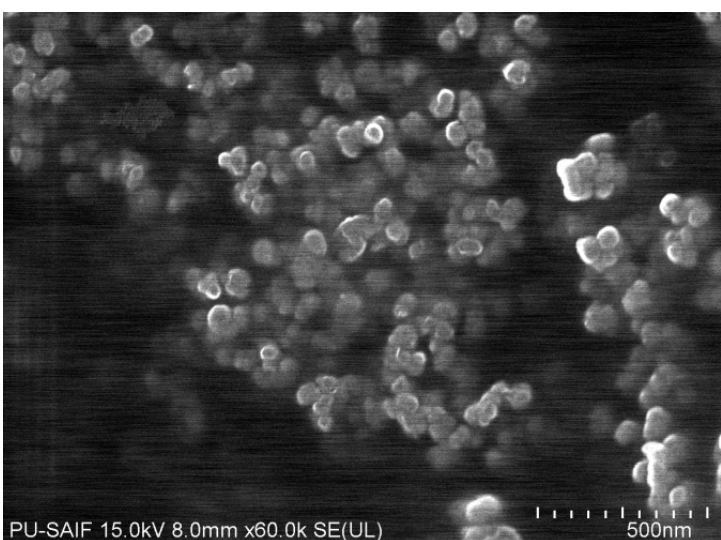

Figure 1: FE-SEM of $\mathrm{CuO}$ nanoparticles

Table 1 presented the thermo physical properties of $\mathrm{CuO}$ nanoparticles. Dispersion technique was used for the preparation nanofluids.

Two sample nanofluids were prepared with different volume concentrations $-0.3 \%$ and $0.7 \%$ of $\mathrm{CuO}$ nanoparticles without adding any additive. In order to ensure even and required dispersion of nanoparticles in the base fluid $\mathrm{pH}$ of nano fluid was maintained at 5 for $\mathrm{CuO}$ nano fluid. It was found that the prepared copper oxidebased nano fluid was stable for ten days.

Table 1: Thermo-physical properties of both nanoparticles Nanoparticles Density $(\rho) C_{p}(\mathrm{~J} / \mathrm{kg} \mathrm{K}) \quad \mathrm{k}(\mathrm{W} / \mathrm{m} \mathrm{K})$

\begin{tabular}{llcc} 
type & $\left(\mathrm{kg} / \mathrm{m}^{3}\right)$ & & {$[14]$} \\
\hline $\mathrm{CuO}$ & 6500 & 533 & 76.5
\end{tabular}

\section{RESULTS}

Key physical properties of both base fluid and the prepared nano fluid were measured using instruments like standard viscometer (Ubbelohde make) for viscosity measurement and thermal properties analyser (Decagon devices, Inc., USA) for thermal conductivity. Thermo-physical properties of the prepared nano fluid and base fluids are measured at a temperature range of $20{ }^{\circ} \mathrm{C}$ to $40{ }^{\circ} \mathrm{C}$. The specific heat for the employed base fluid was cited from literature [15] and used later in calculations.

Properties of propylene glycol and water mixture (base fluid)

Density (Refer Figure 2)

$\rho_{\mathrm{PG} / \mathrm{W}}=-0.002 \mathrm{~T}^{2}-0.532 \mathrm{~T}+1053$

Specific heat

$C_{p_{P G / W}}=4.43 T+3252$

Viscosity (Refer Figure 3)

$\mu_{P G / W}=21.7 e^{-0.04 T}$

Thermal conductivity (Refer Figure 4)

$k_{P G / W}=-1 \times 10^{-5} T^{2}+0.0014 T+0.300$

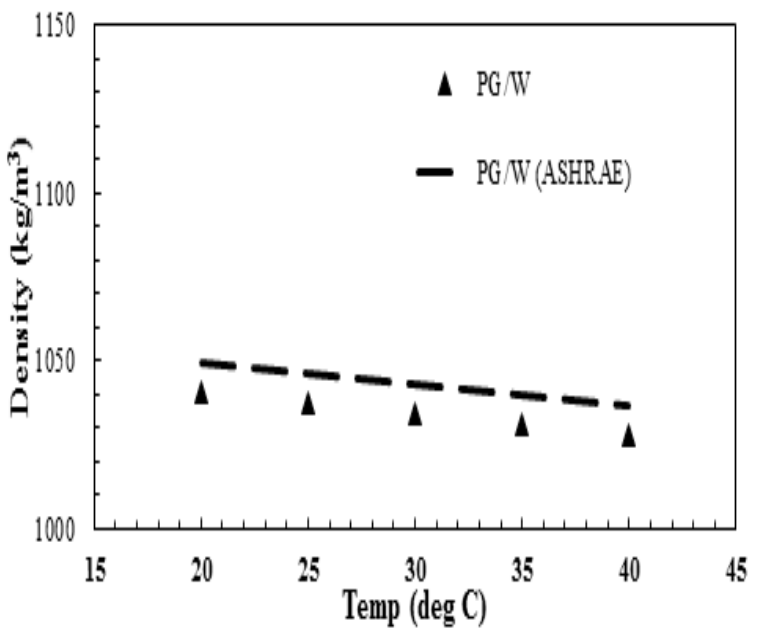

Figure 2: Density variation behavior of base fluid with temperature.

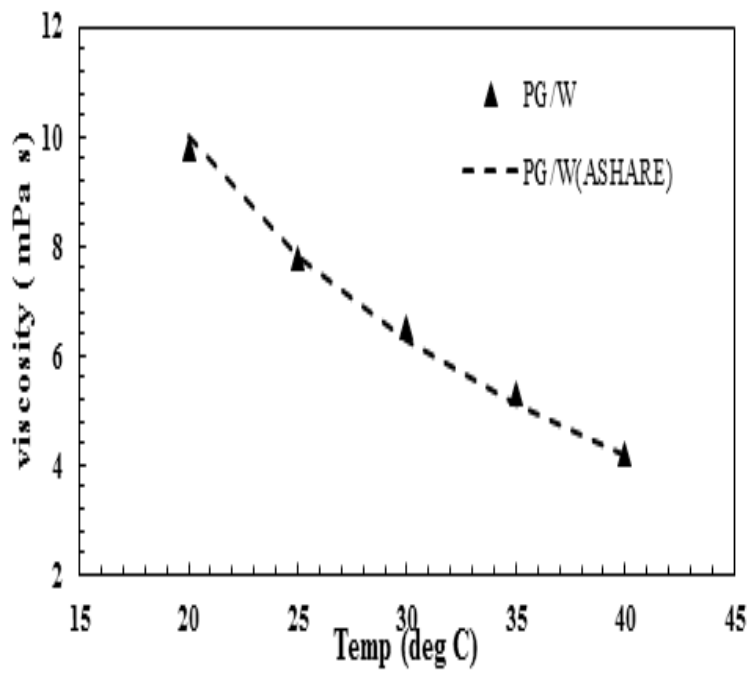

Figure 3: Viscosity variation in base fluid with respect to temperature.

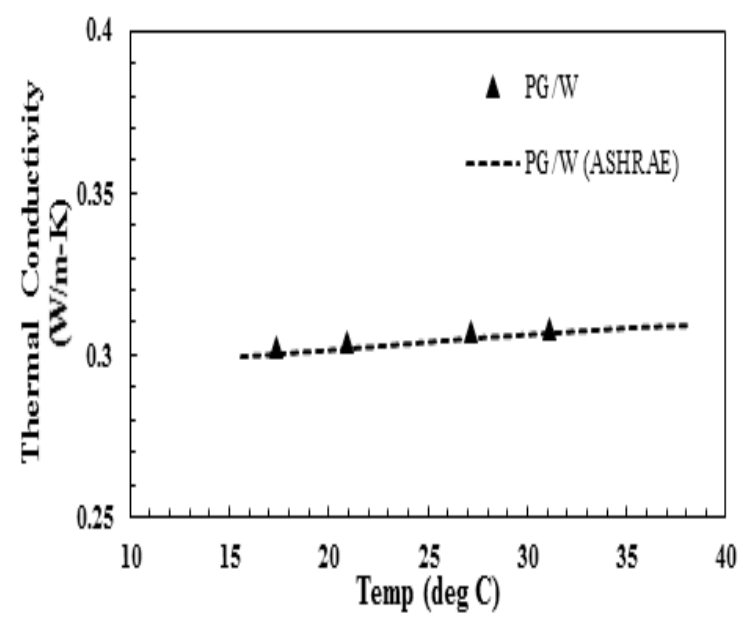

Figure 4: Variation in thermal conductivity of base fluid with respect to temperature. 


\section{Thermo - physical properties of nanofluid}

\section{Density}

Density of the prepared nanofluids with various volume concentrations was determined through experiments at different temperature and validated using equation [10]

$\rho_{\mathrm{nf}}=\rho_{\mathrm{p}} \Phi+\rho_{\mathrm{bf}}(1-\Phi)$

Where $\rho_{\mathrm{nf}}, \phi, \rho_{p}$, and $\rho_{b f}$ represents nanofluid density, particle volume fraction, density of nanoparticles and density of base fluid respectively.

Specific heat

The specific heat of nano fluid was estimated by equation [10]:

$$
C_{p_{n f}}=\frac{\Phi\left(\rho C_{p)}+(1-\Phi)\left(\rho C_{p)_{b f}}\right.\right.}{\Phi \rho_{p}+(1-\Phi) \rho_{b f}}
$$

\section{Viscosity}

The Ubbelohde viscometer was employed to determine viscosity of a measured volume of the prepared nano fluid at different temperatures. The obtained values were found to be comparable with the correlation available in the literature [15]. Figure 5 shows the temperature dependency of viscosity for 1.0 volume percent. Hence for other concentrations also the following correlation was used. $\frac{\mu_{n f}}{\mu_{P G / W}}=A \exp \left(B \phi+C \frac{T_{0}}{T^{\prime}}\right)$ where $A=1.7225, B=$

$18.7338 \& C=-0.60339$

$\mathrm{T}_{\mathrm{o}}$ and $\mathrm{T}^{\prime}$ are the reference and bulk fluid temperatures in $\mathrm{K}$ respectively.

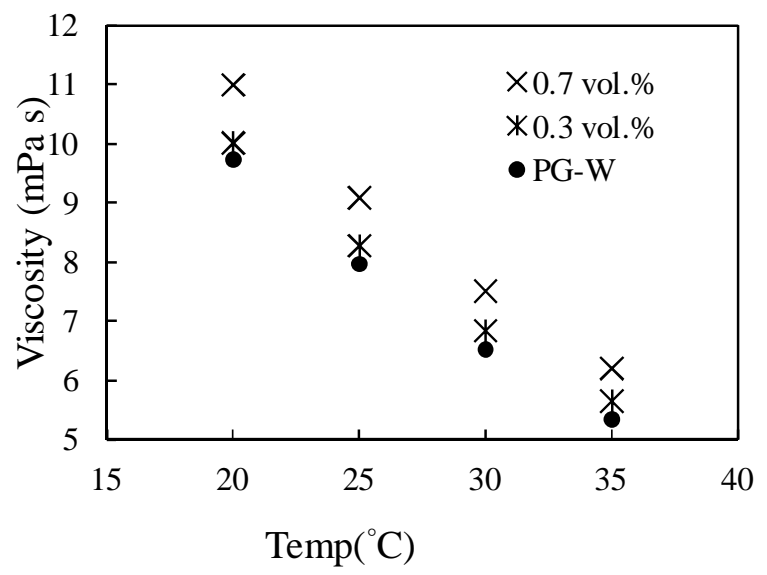

Figure 5: Viscosity of 1.0 volume percent of $\mathrm{CuO} / \mathrm{PG}-$ Thermal Conductivity $\mathrm{W}$ nano fluid

A battery-operated instrument known as $\mathrm{KD}_{2}$ Pro thermal property analyzer (Decagon Devices, Inc., USA) was employed to ascertain the thermal conductivity of the prepared nano fluid. Readings of thermal conductivity were recorded at regular time interval after sonicating the samples for 1 hour. Average of the obtained readings was used to determine the final thermal conductivity. Figure 6 shows the variation of thermal conductivity of $\mathrm{CuO}$ nanofluids with temperature.

Experimental data points were compared with the different models available in literature and was found to be well agreed with following model [16]. $k_{n f}=\frac{k_{p}+2 k_{b f}-2\left(k_{b f}-k_{p}\right) \Phi}{k_{p}+2 k_{b f}+\left(k_{b f}-k_{p}\right) \Phi} k_{b f}+5 \times 10^{4} \beta \Phi \rho_{b f} C_{p_{b f}} \sqrt{\frac{\kappa T}{\rho_{p} d_{p}}} f(T, \Phi$

The first term in equation (9) represents the static conductivity whereas the latter part is the dynamic portion which arises due to increased conductivity due to Brownian motion. Model [16] derived the function $\mathrm{f}(\mathrm{T}, \Phi) \& \beta$ as follows:

$$
\begin{aligned}
& \quad f(T, \Phi)= \\
& \left(2.8217 \times 10^{-2} \Phi+3.917 \times 10^{-3}\right)\left(\frac{T}{T_{0}}\right)+\left(-3.0669 \times 10^{-2} \Phi-\right. \\
& \left.3.9112310^{-3}\right) \\
& \text { and } \beta=9.881(100 \Phi)^{-0.9446}
\end{aligned}
$$

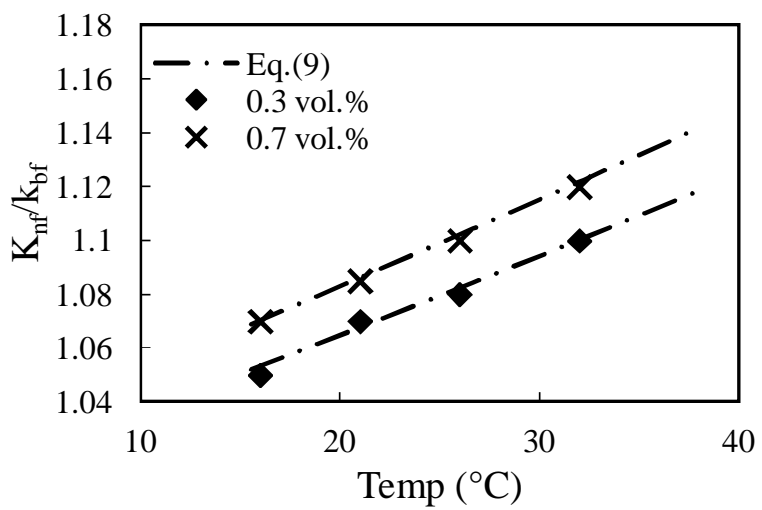

Figure 6: Thermal conductivity of $\mathrm{CuO} /(\mathrm{PG}+\mathrm{W})$ nano fluid

\section{Experimental setup}

The test rig comprised of a concentric chamber, inlet copper tube and outer stainless-steel tube of $13 \mathrm{~mm}$ and $40 \mathrm{~mm}$ diameter respectively (refer Figure 7). The hot fluid is made to enter through the outer section so as to maintain boundary conditions of constant wall temperature. Thermocouples are set for temperature measurement at equal distances from each other. The bulk temperature of the test fluid was measured by two ( $\mathrm{k}-$ type) thermocouples - each for inlet and outlet sections. For minimum heat loss, the entire test section was insulated with thick glass wool followed by aluminium cladding as shown in Figure 7.

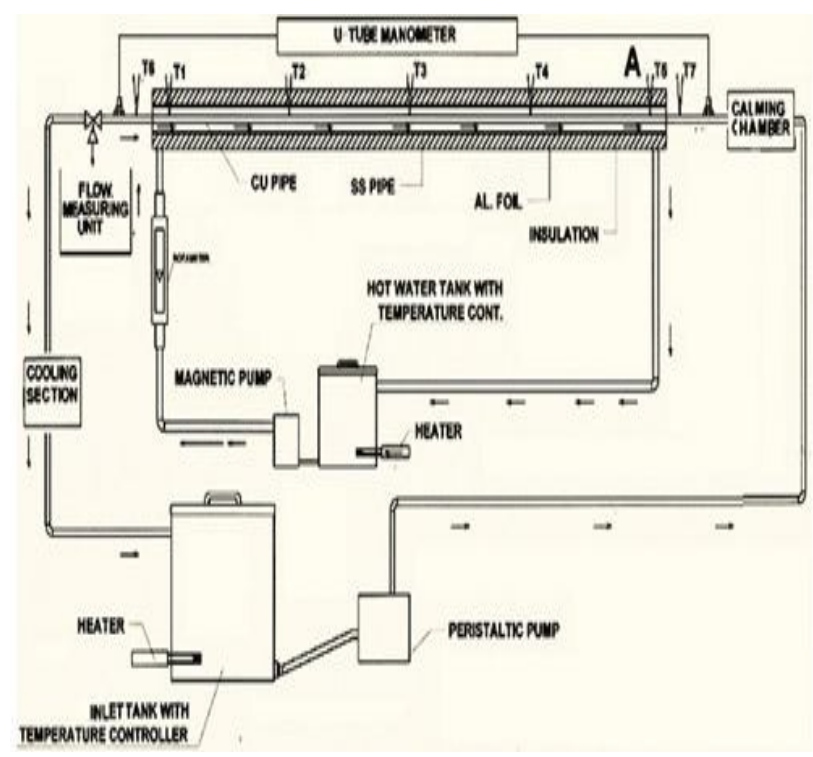

Figure7: Straight tube schematic diagram 


\section{DISCUSSION}

It is to be noted that distilled water was used to calibrate the test rig. The obtained experimental results were well predicted by Seider-Tate Equation (13) for laminar flow as shown in Figure 8.

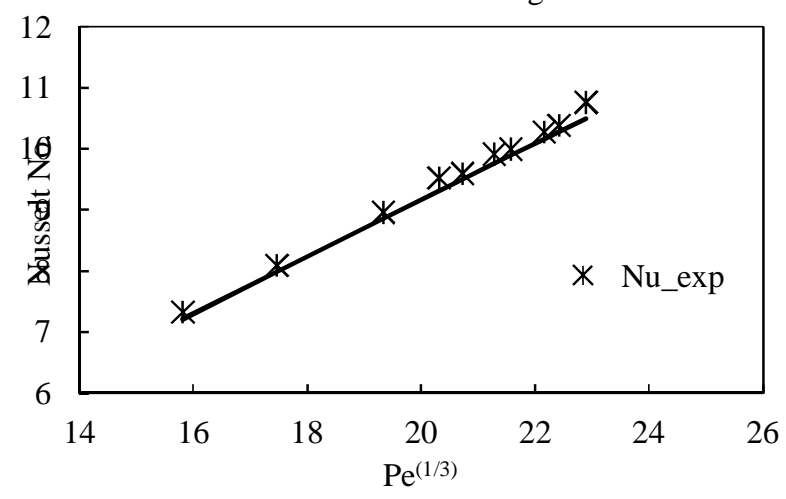

Figure 8: Nusselt number vs. Peclet number for distilled water

Under laminar flow conditions, i.e. $\operatorname{Re}<2100$, Seider Tate Equation [17] is given as under:

$\mathrm{Nu}=1.86\left(\operatorname{Re} \cdot \operatorname{Pr} \cdot \frac{\mathrm{d}}{\mathrm{L}}\right)^{1 / 3}\left(\frac{\mu}{\mu_{\mathrm{w}}}\right)^{0.14}$

Where $\mu_{w}$ is fluid viscosity at wall temperature, Reynolds Number $\operatorname{Re}=\frac{\mathrm{d}_{\mathrm{i}} \mathrm{v} \rho}{\mu}$ and Prandtl NumberPr $=\frac{\mathrm{C}_{\mathrm{p}} \mu}{\mathrm{k}}$.

Figure 9 shows the variation in Nusselt number of the base fluid i.e. PG/water $(60: 40$, by wt.\%) with respect to the flow behavior or Reynolds number. It is clear from Figure 13 that the modified Nusselt number $\left(\mathrm{Nu}_{\text {modified }}\right)$ of the copper oxide nanofluids is higher than those of the base fluid and it increases with the increased Peclet number and particle volume concentration.

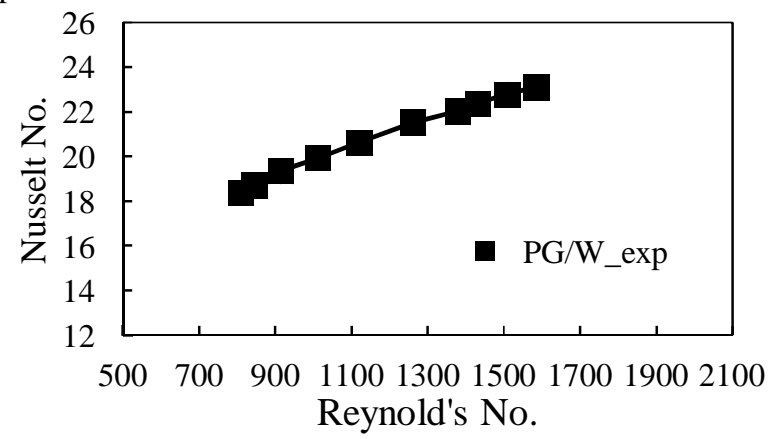

Figure 9: Variation in Nusselt number with respect to Reynolds number of base fluid

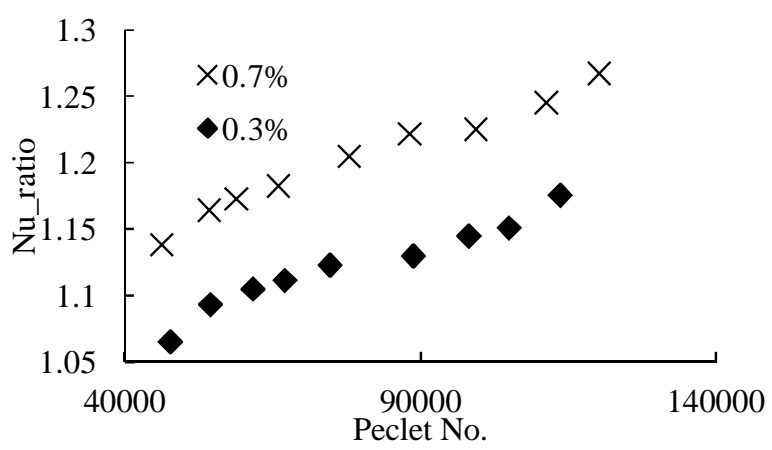

Figure 10: Nusselt no. ratio v/s Peclet no. for copper oxide nano fluid at $0.3 \% \& 0.7 \%$ volume concentrations.
As seen in Figure 10 in the case of 0.7 vol. $\%$ concentration, Nusselt no. increases to $17 \%$ w.r.t base fluid and $26 \%$ when Peclet no. rise from 48000 to 123000. Also, for a Peclet number of around 64000, 0.7 vol.\% shows an enhancement of $18 \%$ w.r.t base fluid whereas 0.3 Vol. $\%$ shows the enhancement of $12 \%$. Enhanced heat transfer performance of the prepared nanofluids is due to increased thermal conductivity resulting from addition of nanoparticles.

$\mathrm{Nu}_{\text {ratio }}=\frac{\mathrm{Nu}_{\text {nanofluid }}}{\mathrm{Nu}_{\text {basefluid }}}$

Figure 11 shows graph between ratios of heat transfer coefficients of the copper oxide nano fluid and base fluid at different volume concentrations within the range of Reynolds no. from 750 - 1600. This ratio clearly shows the enhancement of nanofluids w.r.t base fluid and it increases with increase in particle volume concentration. For a Reynolds number of 780 , for $0.3 \%$ volume concentration the heat transfer enhancement is $20 \%$ and for Reynolds number of 1600 , this enhancement is $40 \%$ for a volume concentration of $0.7 \%$. This shows that the thermal conductivity enhancement cannot be the only criteria for high heat transfer enhancement. Hence there are other parameters such as particle migration and thermophoresis in nanofluids, which can be important for high heat transfer enhancement of nanofluids [18].

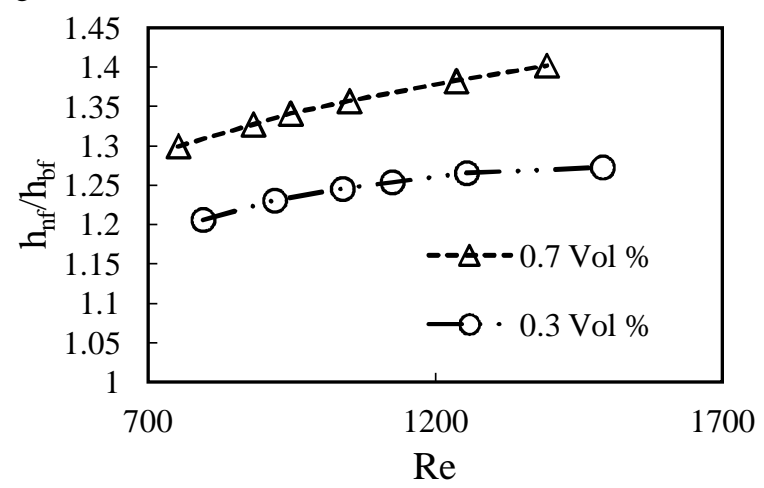

Figure 11: Ratio of heat transfer coefficient versus Reynolds number for $\mathrm{CuO}$ - PG/water nano fluid.

\section{Analysis for uncertainty}

All the measured quantities of variables required to ascertain heat transfer coefficient and Nusselt no. are prone to certain uncertainty due to error in experimental measurements. The uncertainty of individual quantity is estimated and its combined effect on derived quantities is also estimated and presented here. The uncertainty analysis has been carried out on the basis of the suggestion made by [19-20].

Estimation of uncertainty in reynolds number

Reynolds number is defined as $\operatorname{Re}=\frac{d_{t} v \rho}{\mu}$, the relative uncertainty in Reynolds number is calculated

$\mathrm{u}_{\mathrm{Re}}=\left[\left(\frac{\mathrm{d}_{\mathrm{t}}}{\operatorname{Re}} \frac{\partial \mathrm{Re}}{\partial \mathrm{d}_{\mathrm{t}}} \mathrm{u}_{\mathrm{d}_{\mathrm{t}}}\right)^{2}+\left(\frac{\mathrm{v}}{\operatorname{Re}} \frac{\partial \mathrm{Re}}{\partial \mathrm{v}} \mathrm{u}_{\mathrm{v}}\right)^{2}+\left(\frac{\rho}{\operatorname{Re}} \frac{\partial \mathrm{Re}}{\partial \rho} \mathrm{u}_{\rho}\right)^{2}+\right.$

$\left.\left(\frac{\mu}{\operatorname{Re}} \frac{\partial \operatorname{Re}}{\partial \mu} \mathrm{u}_{\mu}\right)^{2}\right]^{1 / 2}$

Thus the relative uncertainty in the individual quantities like $\mathrm{u}_{\mathrm{d}_{\mathrm{t}}}, \mathrm{u}_{\mathrm{v}}, \mathrm{u}_{\rho}$ and $\mathrm{u}_{\mu}$ are used to determine the relative uncertainty in Reynolds number. 
Estimation of uncertainty in nusselt number

Nusselt number is defined as $\mathrm{Nu}=\frac{\mathrm{hd}_{\mathrm{t}}}{\mathrm{k}}$

The relative uncertainty in Nusselt number is calculated

$\mathrm{u}_{\mathrm{Nu}}=\left[\left(\frac{\mathrm{d}_{\mathrm{t}}}{\mathrm{Nu}} \frac{\partial \mathrm{Nu}}{\partial \mathrm{d}_{\mathrm{t}}} \mathrm{u}_{\mathrm{d}_{\mathrm{t}}}\right)^{2}+\left(\frac{\mathrm{h}}{\mathrm{Nu}} \frac{\partial \mathrm{Nu}}{\partial \mathrm{h}} \mathrm{u}_{\mathrm{h}}\right)^{2}+\left(\frac{\mathrm{k}}{\mathrm{Nu}} \frac{\partial \mathrm{Nu}}{\partial \mathrm{k}} \mathrm{u}_{\mathrm{k}}\right)^{2}\right]^{1 / 2}$

Thus, the relative uncertainty in the individual quantities like $\mathrm{u}_{\mathrm{d}_{\mathrm{t}}}, \mathrm{u}_{\mathrm{h}}$, and $\mathrm{u}_{\mathrm{k}}$ are used to determine the relative uncertainty in Nusselt number. Uncertainty analysis for independent variables are reported in Table 2. The maximum and the minimum values of uncertainty for the derived variables for straight tube are presented in Table 3.

Table 2: Uncertainty analysis for independent quantities

\begin{tabular}{|l|c|l|c|}
\hline Quantity & Uncertainty & Quantity & Uncertainty \\
\hline $\mathrm{dt}(\mathrm{m})$ & $\pm 1.00 \mathrm{E}-05$ & $\mathrm{t}(\mathrm{s})$ & \pm 0.01 \\
\hline $\mathrm{L}(\mathrm{m})$ & \pm 0.001 & $\mathrm{~m}(\mathrm{~kg})$ & \pm 0.01 \\
\hline $\mathrm{T}\left({ }^{\circ} \mathrm{C}\right)$ & \pm 0.1 & $\rho(\mathrm{kg} / \mathrm{m} 3)$ & \pm 0.1 \\
\hline
\end{tabular}

Table 3: Maximum and the minimum values of uncertainty

\begin{tabular}{|c|c|c|}
\hline Quantity & $\begin{array}{c}\text { Maximum } \\
\text { uncertainty }\end{array}$ & $\begin{array}{c}\text { Minimum } \\
\text { uncertainty }\end{array}$ \\
\hline$\dot{m}(\mathrm{~kg} / \mathrm{s})$ & $\pm 1.77 \mathrm{E}-03$ & $\pm 1.64 \mathrm{E}-03$ \\
\hline $\mathrm{Q}(\mathrm{m} 3 / \mathrm{s})$ & $\pm 1.65 \mathrm{E}-06$ & $\pm 1.59 \mathrm{E}-06$ \\
\hline $\mathrm{v}(\mathrm{m} / \mathrm{s})$ & $\pm 4.26 \mathrm{E}-03$ & $\pm 4.09 \mathrm{E}-03$ \\
\hline $\mathrm{U}(\mathrm{W} / \mathrm{m} 2 \mathrm{~K})$ & \pm 3.301 & \pm 3.073 \\
\hline $\mathrm{h}(\mathrm{W} / \mathrm{m} 2 \mathrm{~K}))$ & \pm 5.285 & \pm 4.660 \\
\hline $\mathrm{Re}$ & \pm 21.378 & \pm 14.187 \\
\hline $\mathrm{Nu}$ & \pm 0.360 & \pm 0.307 \\
\hline
\end{tabular}

\section{Data analysis}

Based upon the experimental data of $\mathrm{CuO}$ - PG/water nano fluid for all volume concentrations, a new correlation for straight tube have been proposed and is as follows:

$\mathrm{Nu}_{\text {ST_modified }}=\frac{\mathrm{Nu}_{\exp }}{\left(\frac{\mathrm{d}}{\mathrm{L}}\right)^{1 / 3}\left(\frac{\mathrm{u}_{\mathrm{nf}}}{\mu_{\mathrm{wnf}}}\right)^{0.14}}=1.86\left(\mathrm{Pe}^{1 / 3}\right)\left[1+\mathrm{m}\left(\frac{\Phi}{1-\Phi}\right)^{\mathrm{n}}\right]$

Other errors like average relative error (ARE) and mean relative quadratic error (MRQE) were also calculated.

$$
\text { M.R.Q.E. }=\sqrt{\frac{\left(\frac{\text { experimental }- \text { theroetical }}{\text { experimental }}\right)^{2}}{N-1}} \text { and }
$$

A.R.E. $=\frac{100}{\mathrm{~N}}\left|\frac{\text { experimental }- \text { theroetical }}{\text { experimental }}\right|$ where $\mathrm{N}$ is the no. of data points.

Constants $\mathrm{m} \& \mathrm{n}$ were obtained as $\mathrm{m}=1.87$ and $\mathrm{n}=0$, using regression analysis. New proposed correlation were also compared with available correlations in literature. Table 4 shows the comparison based on statistical errors.

Table 4: Statistical errors for $\mathrm{CuO}$ nanofluids in Straight tube

\begin{tabular}{ccc}
\hline Correlations & MRQE & ARE \% \\
\hline New correlation (Eq. 15) & 0.03 & 2.3 \\
Correlation [21] & 0.81 & 78.06 \\
\hline
\end{tabular}

Further to check the validity of present proposed correlation, its applicability was verified using experimental data of other researchers available in literature. The same comparison is represented graphically as a parity plot in Figure 12 .

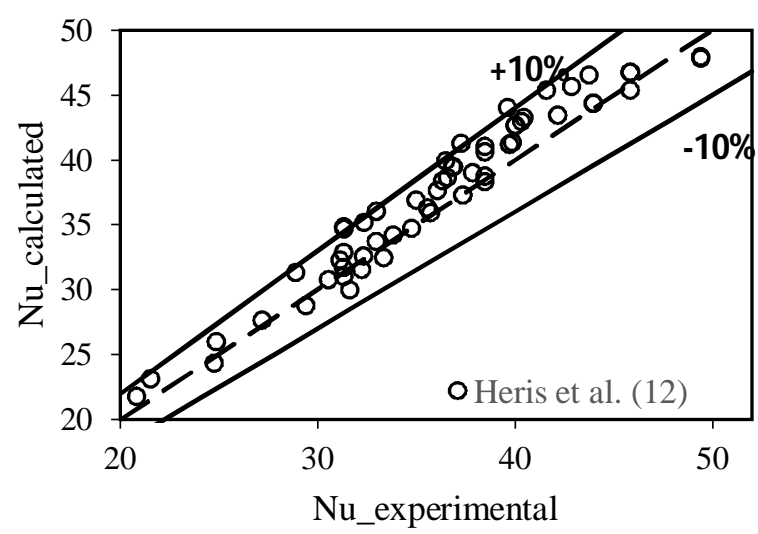

Figure 12: Parity plot b/w the theoretically calculated and experimentally obtained $\mathrm{Nu}$ for a straight tube setup.

The experimental data of [18] was used for comparison in Figure 12 was for $\mathrm{CuO}$ nanoparticles with water as base fluid. As can be seen from the above parity plot the present proposed correlation predicted both the data sets quite well in the range of $\pm 10 \%$. Thus, the validity of this proposed correlation can be extended to water based $\mathrm{CuO}$ nanofluids as well.

\section{CONCLUSION}

Heat transfer through forced convection in sample copper oxide - propylene glycol nanofluids $(0.3 \& 0.7$ vol.\%) under constant wall temperature boundary condition and laminar regime through straight tube was investigated, and were concluded that the Thermophysical properties of both the prepared copper oxide nanofluids were determined experimentally within a temperature range of $20-35^{\circ} \mathrm{C}$. Further, the obtained experimental results showed that thermal conductivity of the prepared nano fluid increased by $14 \%$ and $10 \%$ for volume concentrations of $0.7 \%$ and $0.3 \%$ respectively at $32^{\circ} \mathrm{C}$.

Convective heat transfer coefficient of the employed base fluid was found to be less than both the nano fluid. The convective heat transfer coefficient and Nusselt no. of the tested nano fluid increased with rise in Reynolds number and particle volume fraction. The detailed analyses of the obtained results exhibit that heat transfer characteristics of both the nanofluids resulted from the following:

- Increased specific surface area per unit volume of the nanoparticles.

- Increased heat capacity and the apparent thermal conductivity of the fluid

- Increased local turbulence caused by random interaction and collision among nanoparticles resulting in flattening of local temperature profile within the nano fluid.

A new empirical relation as a function of particle volume fraction is proposed in the form of Equation 15 in order to estimate Nusselt no. of copper oxide-based nano fluid flowing through straight tube. This correlation also predicts the experimental data available in literature, within range of $\pm 10 \%$.

Author Contributions: The design of the experiments and experimental procedures were carried out by the first 
author. Also, he prepared the nanofluids and carried out the stability.

Dr. Amandeep carried out characterization of the prepared stable nanofluids.

Dr. Parag did detailed analysis of the results and carried out uncertainty analysis.

Funding: The authors would like to acknowledge the financial support from DST-PURSE-II (Ref. no. 7981/RPC) as fellowship to carry out research work.

Conflicts of Interest: "The authors declare no conflict of interest."

\section{REFERENCES}

[1] A. Sobti and R.K. Wanchoo, "Thermal Conductivity of Nanofluids." Materials Science Forum, vol. 757, pp. 111-137, 2013.

https://doi.org/10.4028/www.scientific.net/MSF.757.111

[2] P. Keblinski, J.A. Eastman and D. G. Cahill "Nanofluids

for thermal transport." Materials Today, vol. 8, (6), pp. 3644, 2005.

https://doi.org/10.1016/S1369-7021(05)70936-6

[3] X.-Q. Wang and A.S. Mujumdar, "Heat transfer characteristics of nanofluids: a review." International journal of thermal science, vol. 46, (1), pp. 1-19, 2007. https://doi.org/10.1016/j.ijthermalsci.2006.06.010

[4] S. Murshed, K. Leong and C. Yang, "Thermophysical and electrokinetic properties of nanofluids-a critical review." Applied Thermal Engineering, vol. 28, (17), pp. 2109-2125, 2008.

https://doi.org/10.1016/j.applthermaleng.2008.01.005

[5] S. K. Das, S. U. S Choi and H. E.Patel,. "Heat Transfer in Nanofluids-A Review." Heat Transfer Engineering, vol. 27, (10), pp. 3-19, 2006.

https://doi.org/10.1080/01457630600904593

[6] J.A. Eastman, S.R. Phillpot, S.U.S . Choi .and P. Keblinski, "Thermal Transport in Nanofluids." Annual Reviews in Material Research, vol. 34, pp. 219-246, 2004.

https://doi.org/10.1146/annurev.matsci.34.052803.090621

[7] D. Wen, G. Lin, S. Vafaei and K. Zhang, "Review of nanofluids for heat transfer applications." Particuology, vol. 7, (2), pp. 141-150, 2009.

https://doi.org/10.1016/j.partic.2009.01.007

[8] S.U.S. Choi, D.A. Singer and H.P. Wang, "Developments and Applications of Non-Newtonian Flows." vol. FED 231, p 99, 1995.

[9] R. Gupta, Parminder Singh and R.K. Wanchoo, "Heat Transfer Characteristics of Nano-Fluids." Materials Science Forum, vol. 757, pp. 175-195, 2013,. https://doi.org/10.4028/www.scientific.net/MSF.757.175

[10] , B. Pak. and Y.I. Cho, "Hydrodynamic and Heat Transfer Study of Dispersed Fluids with Submicron Metallic Oxide Particle." Experimental Heat Transfer, 11, pp. 151-170, 1998.

https://doi.org/10.1080/08916159808946559

[11] Z.S. Heris, S.G. Etemad and M. Nasr Esfahany, “ Experimental investigation of oxide nanofluids laminar flow convective heat transfer." International Communications in Heat and Mass Transfer, vol. 33, (4), pp. 529-535, 2006,. https://doi.org/10.1016/j.icheatmasstransfer.2006.01.005 [12] P. Razi, M.A Akhavan-Behabadi and M. Saeedinia, "Pressure drop and thermal characteristics of $\mathrm{CuO}-$ base oil nanofluid laminar flow in flattened tubes under constant heat flux." International Communications in Heat and Mass Transfer, vol. 38(7), pp. 964-971, 2011.

https://doi.org/10.1016/j.icheatmasstransfer.2011.04.010

[13] S. Suresh, K.P. Venkitaraj, P. Selvakumar and M. Chandrasekar, "Effect of Al2O3-Cu/water hybrid nanofluid in heat transfer." Experimental Thermal and Fluid Science, vol. 38, pp. 54-60, 2012.

https://doi.org/10.1016/j.expthermflusci.2011.11.007

[14] R.S. Vajjha, D.K. Das and D.P. Kulkarni,. "Development of new correlations for convective heat transfer and friction factor in turbulent regime for nanofluids." International Journal of Heat and Mass Transfer, vol.53, (21-22), pp. 4607-4618, 2010.

https://doi.org/10.1016/j.ijheatmasstransfer.2010.06.032

[15] American Society of Heating, R.; Air-Conditioning, E. ASHRAE Handbook : Fundamentals - SI edition. American Society of Heating Refrigerating and Air-Conditionin: Atlanta, Ga, 2005.

[16] J. Koo and C. Kleinstreuer, "Impact analysis of nanoparticle motion mechanisms on the thermal conductivity of nanofluids." International Communications in Heat and Mass Transfer, vol. 32(9), pp. 1111-1118, 2005. https://doi.org/10.1016/j.icheatmasstransfer.2005.05.014

[17] E.N. Sieder and G.E. Tate, "Heat Transfer and Pressure Drop of Liquids in Tubes." Industrial \& Engineering Chemistry, vol. 28, (12), pp. 1429-1435, 1936.

https://doi.org/10.1021/ie50324a027

[18] M.M Heyhat and F. Kowsary, "Effect of Particle Migration on Flow and Convective Heat Transfer of Nanofluids Flowing Through a Circular Pipe." Journal of Heat Transfer, vol. 132, (6), pp. 062401-062401, 2010.

https://doi.org/10.1115/1.4000743

[19] S. J. Kline, The description of uncertainties in single sample experiments. Mech. Engg., 75, pp. 3-9,1953.

[20] J.M. Robert, Describing the uncertainties in experimental results, 1988.

[21] K.V. Sharma and L. Syam, "Laminar convective heat transfer and friction factor of $\mathrm{Al} 2 \mathrm{O} 3$ nanofluid in circular tube fitted with twisted tape inserts." International Journal of Automotive and Mechanical Engineering (IJAME), vol. 3, pp. 65-278, 2011.

https://doi.org/10.15282/ijame.3.2011.4.0023 